\title{
EXPANDING DEMAND FOR ONLINE HIGHER EDUCATION: SURVEYING PROSPECTIVE STUDENTS
}

\author{
Richard Garrett \\ Senior Analyst, Eduventures, LLC
}

\begin{abstract}
The Eduventures survey examined next-generation demand for online postsecondary education, assessing online experience, delivery mode and marketing channels preferences, and perceptions of price, quality and location, identifying key takeaways in each area.
\end{abstract}

\section{KEYWORDS}

Perceptions, Delivery Mode, Age, Credential, Discipline, Price, Geography, Prior Educational Experience

\section{INTRODUCTION}

In June 2006, Eduventures, LLC surveyed over 2,000 consumers interested in postsecondary education in the next three years [1]. The objective of the study was to better understand next-generation demand for online higher education, and to get a clearer sense of how large the market may become. "Online higher education" is used here to mean wholly online programs/courses, where attendance at a physical campus is rare or not required. On behalf of members of Eduventures' Online Higher Education (OHE) program, OHE staff gathered a unique dataset, offering greater detail than ever before on consumer views and preferences, and permitting valuable insights into the development of online higher education in the United States.

Eduventures estimates that at the close of 2005, wholly online higher education accounted for only $7 \%$ of higher education students in the United States (c.1.2 million students). How big might this market become? Will online come to represent $15 \%$ of the market, and by when? Is $25 \%$ or higher realistic, and in what time frame?

Eduventures’ Assessing Consumer Attitudes Toward Online Education report in May 2005 [2], found that a significant majority of consumers reported either uncertainty or negative views about online higher education. The report argued that what were termed Believers (i.e. consumers predisposed to the value proposition of online higher education) accounted for the vast majority of online enrollments to date, but cautioned that increased competition risked market saturation. To circumvent competition, universities and colleges must move beyond the increasingly cutthroat Believer segment, and begin to address the needs and values of the wider population. Building on the findings of Eduventures' Competing in Online Higher Education report in February 2006 [3], improved understanding of consumer views and motivations resulting from this new study, will help OHE members pinpoint robust positioning and differentiation strategies.

It is important to determine the accuracy and stability of three categories (Believer, Fence-Sitter, Skeptic), 
and the extent to which consumers are moving from one category to another, based on increased exposure to online delivery, or other factors. It is also critical to ascertain how different consumers build up a view of online higher education, what such views are based on, and what channels online universities and colleges might use to reach particular groups. Interest in online relative to key demographics (e.g., age, ethnicity, prior education), and less tested variables (e.g., location of the institution offering online provision, and institutional control) are important questions. How do consumers think about teaching and learning in higher education, and how is online delivery seen to fit into the equation?

Staff of Eduventures' Online Higher Education (OHE) program [4] developed a project proposal and survey tool, refined by OHE members. The survey elicited 2,033 qualified consumer responses from across the country. Consumers were qualified in three ways:

1. Age - must be at least 16 years old;

2. Residence - must reside in the United States;

3. Interest in postsecondary study - must anticipate enrolling in a course, including non-credit courses, degree, certificate, or other program at a college/university within the next three years.

To provide hard number estimates of the total addressable market stratified by delivery mode, in a number of places both reports model to the U.S. adult population interested in postsecondary education in the next three years.

\section{KEY TAKEAWAYS}

The following is a high-level summary of the key findings of the study.

\section{A. Demand for Postsecondary Education}

- Interest in postsecondary education. Out of a total surveyed population of 4,660, 44\% indicated interest in postsecondary education in the next three years.

- Addressable population. Based on a $44 \%$ reported rate of interest, the modeled total addressable U.S. market for postsecondary education is around 103 million people.

Key takeaway: Reported interest in postsecondary education suggests a potentially massive market opportunity. Of course, "interest" and enrollment are distinct. Based on enrollment trends, a 5:1 interest/enrollment ratio is projected. Online providers' differentiation and marketing strategies will play a role in improving this ratio.

\section{B. Online Experience, Preference \& Likelihood}

- Online experience. Almost one-third of respondents cited experience of a wholly online or blended course, while around 6\% reported experience of a wholly online program (e.g. degree or certificate). Fifty-five percent of the sample claimed no online postsecondary experience. When blended delivery was factored in, non-experience dropped to $48 \%$.

- Delivery mode preference. There is an encouraging gap between current experience of wholly online programs (6\%) and stated preference for this mode of delivery (19\%). More generally, around $50 \%$ of consumers say they prefer a mode of delivery either dominated by online or at least balanced between online and on-campus. 
- Delivery mode \& “likelihood.” The survey distinguished between delivery mode preference and "real world” decision-making. For example, $19 \%$ of consumers expressed a preference for wholly online delivery, but $41 \%$ said, given other factors, that it was "likely" they would undertake a program/course wholly online in the next three years.

Key takeaway: Extraordinary openness to forms of online delivery means consumers are receptive to messaging from online providers. The fact that "likelihood" to take an online program exceeds "preference," suggests other factors at work (e.g., convenience) that may permit tradeoffs against first choice. This tension between preference and likelihood is key to understanding effective messaging.

\section{Delivery Mode: Age, Credential \& Discipline}

- Delivery mode preference \& age. The two youngest age bands expressed strong preference for campus-based study, and were most open to online when it constituted a minority component of a campus-based experience. For the 25-34 age group, campus-dominant options retain priority, alongside much stronger interest in online-dominant options. For the 35-44 and 45-54 age groups, campus-based study falls out of favor, dropping into last place; and online options vie for prominence. However, for the two oldest age groups, campus-dominant options experience a resurgence, particularly for the 65 and older category.

- Delivery mode \& discipline. There was clear clustering of disciplinary interest in terms of general scale and delivery mode preference. Business, IT, education, and healthcare continue to offer the best combination of scale and online interest, but consumers interested in a wide range of other disciplines also exhibited openness to online delivery.

- Delivery mode \& credential. By credential, prospective students interested in associate, bachelor's and master's degrees were most open to wholly online delivery. These consumers were also open to campus-based and blended delivery. Irrespective of credential of interest, most respondents were similarly open-minded.

Key takeaway: The survey reveals consumer interest in online delivery by age, credential and discipline in line with market trends to date. Working adults, degrees and a small number of career-oriented, mass market disciplines remain strongly associated with interest in online delivery. Alongside this predictable configuration, niche/emerging markets among non-traditional age groups, credentials and disciplines are visible. The online higher education market of the future will prove a combination of enduring core and growing diversity. Online providers must determine where best to steer their development relative to this pattern.

\section{Marketing Channels}

- Information sources. Respondents cited online advertising as the most prominent source of information about online programs, but pointed to various personal/neutral sources (e.g., family/friends, faculty/teachers, national rankings) as most influential sources when selecting a school short list.

Key takeaway: Online providers must be careful to distinguish between most prominent and most influential marketing channels. Personal/neutral information sources hold far more weight with consumers, helping them cut through school marketing and increased choice. As the online space becomes more competitive, and schools' differentiation strategies remain relatively under-developed, school-led marketing that emphasizes substantive and distinct value relative to the competition, will win 
consumer attention. In the absence of substantive differentiation, marketing volume (favoring the largest providers) and niche programming will boast an advantage.

\section{E. Perceptions of Quality, Price \& Geography}

- Perceptions of quality. Perceptions of quality suggest a maturation of consumer views - a willingness to assess individual online and on-campus programs on their merits, rather than in terms of delivery mode pure and simple. However, there is also a sustained skeptical minority who continue to regard online delivery in monolithic terms, and as poor quality.

- Perceptions of price. Although $42 \%$ of the sample was willing to judge the quality of individual online programs/courses on their merits, only $27 \%$ were willing to reserve judgment on price. Almost half the sample said they would only be willing to pay less for an online program/course compared to an on-campus experience.

- Online delivery \& geography. Sixty-three percent of respondents who were willing to consider a wholly online program preferred the online provider to have some physical presence (branch campus or main campus) at least within their state. Only 37\% of respondents willing to consider wholly online delivery disregarded location as a factor.

Key takeaway: These trends suggest significant limitations on online higher education in terms of pricing power and marketing reach; and arguably favor local brands over national players. Consumers are open to online delivery, but at the same time exhibit hesitation about value. Noticeable willingness to judge individual online programs on their merits did not translate into comparable willingness to judge price on a per-program basis. Similarly, the majority of consumers most open to online delivery reject the notion of a truly national market, and are more comfortable with combining online delivery and geographical proximity. The challenge for online providers is to refine messaging that bolsters perceptions of quality; and for national players, to emphasize the breadth and depth of the wholly online, remote experience. Both tactics will support greater pricing power.

\section{F. Online Value \& Experience}

- Conceptions of the online value and experience. Alongside strong openness to forms of online delivery, consumers also revealed less positive or narrower conceptions of the nature and value of the online experience. Interest in online appears to be dominated by notions of convenience, and is seen to imply a quality/experience tradeoff.

Key takeaway: Online providers face a tricky balancing act between playing to majority consumer value perceptions centered on convenience, versus emphasizing broader conceptions of online higher education (e.g. around pedagogy, technology). Breadth is essential to overcoming consumer hesitation and allowing individual schools to stand out in an increasingly crowded market. Online providers need to both accommodate and educate consumers.

\section{ABOUT THE AUTHOR}

Richard Garrett is the Senior Research Analyst serving Eduventures' Learning Collaborative program for Online Higher Education. A recent addition to the Eduventures team, Richard is widely regarded as one of Europe's foremost online higher education experts. Prior to joining Eduventures, Richard was deputy director of the Observatory on Borderless Higher Education in the United Kingdom, a position he held from 2001 to 2005. His research and consulting work has focused on higher education trends 
worldwide, particularly online learning, internationalization, and commercial activity. Among his recent publications is E-learning in Tertiary Education- where do we stand?, a 2005 book commissioned by the OECD, Paris. Richard has been quoted in the London Times Higher Education Supplement, Australia's Campus Review, and the South China Morning Post. He has also served as a researcher in the School of Education, University of Surrey and at the Quality Assurance Agency for Higher Education (U.K.). Richard earned both a B.A. and an M.A. from King's College, University of London, as well as a PostGraduate Certificate of Education from the University of Cambridge.

\section{REFERENCES}

1. This consumer study was undertaken under the auspices of Eduventures' Online Higher Education (OHE) program, a membership program that offers universities and colleges a wealth of collaborative and custom research opportunities focused on online higher education. The OHE program helps online providers grow their enrollments, and operate more effectively. The OHE program is privileged to count many of the leading online universities and colleges in the United States among its members. For more information, please visit www.eduventures.com, or contact Richard Garrett, Senior Analyst: rgarrett@eduventures.com,617-532-6081.

2. Eduventures. Assessing Consumer Attitudes Toward Online Education, May 2005.

3. Eduventures. Competing in Online Higher Education, February 2006.

4. Each of these findings is analyzed in more depth in the full reports, available only to members of Eduventures' Online Higher Education program. As part of their membership, universities and colleges that are members of Eduventures' Online Higher Education program are able to draw on a range of data customization services to extract additional detail from the dataset, and commission primary research that speaks to the conclusions of this report. For more information about Eduventures' Online Higher Education program, please visit www.eduventures.com, or contact Richard Garrett, Senior Analyst: rgarrett@eduventures.com, 617-532-6081. 